\title{
University
}

Emslie, C., Lennox, J. and Ireland, L. (2017) The role of alcohol in identity construction among LGBT people: a qualitative study. Sociology of Health and Illness, 39(8), pp. 1465-1479.

There may be differences between this version and the published version. You are advised to consult the publisher's version if you wish to cite from it.

This is the peer reviewed version of the following article Emslie, C., Lennox, J. and Ireland, L. (2017) The role of alcohol in identity construction among LGBT people: a qualitative study. Sociology of Health and Illness, 39(8), pp. 1465-1479, which has been published in final form at http://dx.doi.org/10.1111/1467-9566.12605. This article may be used for non-commercial purposes in accordance with Wiley Terms and Conditions for Self-Archiving.

http://eprints.gla.ac.uk/146558/

Deposited on: 27 September 2017

Enlighten - Research publications by members of the University of Glasgow http://eprints.gla.ac.uk 
"This is the peer reviewed version of the following article: [Emslie, C., Lennox, J. and Ireland, L. (2017), The role of alcohol in identity construction among LGBT people: a qualitative study. Sociol Health Illn.] which has been published in final form at [doi: 10.1111/1467-9566.12605]. This article may be used for non-commercial purposes in accordance with Wiley Terms and Conditions for Self-Archiving."

\section{The role of alcohol in identity construction among LGBT people: qualitative study}

\section{Short title: Drinking and identity construction among LGBT people}

Authors: Carol Emslie ${ }^{1}$, Jemma Lennox ${ }^{2}$ and Lana Ireland ${ }^{1}$

${ }^{1}$ School of Health \& Life Sciences, Glasgow Caledonian University

${ }^{2}$ Formerly Glasgow Caledonian University. Now University of Glasgow

\section{Corresponding Author: Carol Emslie}

School of Health and Life Sciences

Room M410 George Moore Building (c/o Psychology Dept)

Glasgow Caledonian University

Cowcaddens Road

Glasgow, Scotland G4 OBA

Tel: +44 (0)141273 1215

Twitter:@SubMisuseGcu

Jemma Lennox

MRC/CSO Social \& Public Health Sciences Unit

University of Glasgow

Top floor, 200 Renfield Street

Glasgow, Scotland. G2 3QB

Email: jemma.lennox@glasgow.ac.uk

Tel: +44 (0)141353 7500

Lana Ireland

School of Health and Life Sciences

Room M427 George Moore Building (Psychology Dept)

Glasgow Caledonian University

Cowcaddens Road

Glasgow, Scotland G4 0BA

Tel: +44 (0)1412731700

Email: Lana.Ireland@gcu.ac.uk 


\section{The role of alcohol in identity construction among LGBT people: qualitative study}

\section{Abstract (200 words)}

Research suggests that alcohol use and misuse are higher among lesbian, gay and bisexual than heterosexual populations, yet the social context of drinking in sexual minority communities has rarely been examined. To explore lesbian, gay, bisexual and transgender (LGBT) people's relationship with alcohol, we conducted seven focus groups $(\mathrm{N}=33)$ with pre-existing groups of friends and work colleagues (18 to 52 years) in Scotland, UK. We identified and analysed patterns in our data using thematic analysis. Respondents perceived heavy drinking as central to the commercial gay scene. Choice of drink and drinking vessel was an important part of identity construction. Respondents discussed the perception that gay men would drink alcopops and cocktails while lesbians would drink pints of beer. Even when stereotypes were dismissed as inaccurate, they were still thought to pressure people to drink 'appropriately'. Respondents who did not identify as male or female, and those who used drag, were particularly aware of their choice of drink as a means to express identity or to challenge people's preconceptions about gender. Researchers developing interventions to reduce alcohol-related harm in sexual minority populations need to take account of the central role of identity construction in LGBT drinking practices.

Up to 5 Keywords: alcohol, qualitative; drinking cultures; sexual orientation; gender Words count 7944 words (including references and 250 words for table) 


\section{Introduction}

Sexual minority groups (i.e. those who identify as gay, lesbian or bisexual) are more likely to drink alcohol, to drink excessively and to experience alcohol-related problems than those who identify as heterosexual (Allen and Mowbray 2016, Gonzales et al. 2016, Guasp 2011, Hughes and Eliason 2002, Hunt and Fish 2008, Keogh et al. 2009, King et al. 2008, Meads et al. 2009, Varney 2008). For example, Buffin and colleagues (2011) found that 29\% of women and $34 \%$ of men in sexual minority groups in England reported heavy episodic drinking at least once or twice a week in the last month (>8 units of alcohol in a single session for men, $>6$ units for women), compared to $12 \%$ of women and $18 \%$ of men in the general population (Office for National Statistics 2013). Although often grouped together, LGBT (lesbian, gay, bisexual and transgender) people are not a homogenous group (Bloomfield et al. 2011, Hughes and Eliason 2002). Very little is known about drinking in the transgender population (Moncrieff 2014).

It has been suggested that the increased use of alcohol by those who identify as LGBT may be a way of coping with structural factors such as marginalisation, discrimination and stigma and an escape from heterosexist social norms (Peralta, 2008). Alternatively, alcohol may play an important part in social roles. LGBT people are less likely to become parents which is often associated with reduced alcohol consumption - and drinking may be seen as an aid to exploring sexuality, particularly when 'coming out' (Keogh et al. 2009).

Researchers have also noted the centrality of alcohol to the commercial gay scene and the targeted marketing of alcohol to gay men (Drabble 2000). Finally, support services for alcohol problems may not be aware of the barriers LGBT populations face when seeking support, and health professionals may have a lack of familiarity with LGBT social norms (Keogh et al., 2009). 
There is a growing international literature exploring how men and women use alcohol to construct a range of gendered identities (Bobrova et al. 2010, Dumbili 2015, Ho 2015, Simonen et al. 2014, Thurnell-Read 2011, Wolff et al. 2006, Yuan et al. 2010). This is important as policy and intervention responses which ignore the social meanings of healthrelated behaviours are unlikely to be successful (de Visser et al. 2013, Stead et al. 2001). Following West \& Zimmerman (1987), gender is understood as a 'performance' which takes place in social situations and changes across different contexts, rather than as a static property of individuals. 'Doing' gender appropriately creates difference between women and men, and renders gendered social arrangements normal and natural. However, failing to 'do' gender appropriately means that "we as individuals ... may be called to account (for our character, motives, and predispositions)" (p146). Almost thirty years ago, Lemle \& Mishkind (1989) argued that consuming large amounts of alcohol without apparent consequence, drinking alcohol 'straight' (i.e. not diluting it with soft drinks) and drinking beer or 'hard liquor' (as opposed to sweet drinks associated with femininity) were perceived as key components of 'manliness'. More recent qualitative research points to the continuing salience of these social practices for men (Campbell 2000, de Visser and Smith 2007, Emslie et al. 2013, Harnett et al. 2000, Mullen et al. 2007, Willott and Lyons 2012) and highlights the denigration of women and of men positioned as being insufficiently 'manly' to hold their drink (de Visser and Smith 2007, Emslie et al. 2013, Gough and Edwards 1998, Peralta 2007, Willott and Lyons 2012). Women's drinking is often constructed in opposition to men's drinking. For example Emslie and colleagues (2015) found that while women in early midlife used alcohol to construct a range of identities, traditional notions of femininity (e.g. paying attention to their appearance, drinking 'feminine' drinks) remained important. Double standards around gender and alcohol persist; drinking beer (particularly from pint glasses) 
and public drunkenness are still viewed as 'masculine' behaviours in many places, and older or working-class women in particular are positioned as deviant, out of control and embarrassing when perceived to be drinking heavily in public (de Visser and McDonnell 2012, Griffin et al. 2013, Lyons and Willott 2008). However, researchers have also identified more flexible gender practices around drinking (de Visser and Smith 2007, Willott and Lyons 2012). Indeed, it has been argued that drinking may create spaces where men and women can temporarily relax some of the conventions around appropriate gender performances (Emslie et al. 2013, Peralta 2008, Thurnell-Read 2011)

Very few studies have explored how LGBT people use alcohol to construct gender and sexual identities. The scant evidence which exists suggests that clubs and pubs on the commercial gay scene provide spaces apart from the heteronormative world where people can celebrate difference (Peralta 2008), feel 'authentic' (Holt and Griffin 2003) and lose or express themselves through music, dance, drinking and sex (Cáceres and Cortiñas 1996, Valentine and Skelton 2003). Two US studies have taken an in-depth look at how gender and sexuality are (re)constructed by LGBT respondents in gay bars. Caceres \& Cortinas (1996), using a Latino gay bar as a case study, argued that this transgressive space allowed the disruption of structures around gender and sexuality. They suggested drag queens in this bar drew on tools (e.g. clothing, silicone, make up, jewellery, song lyrics) to interrogate gender, and that alcohol acquired "an almost ritualistic necessity as the washing away of a certain part of the self, thus allowing the exploration of assumed identities taboo on the outside" (p255). Peralta (2008) interviewed gay, lesbian and heterosexual students and found drinking was used to justify behaviour which deviated from societal expectations of gender; for example, young gay men discussed relying on alcohol to 'excuse' same-sex sexual behaviour when first coming out. Peralta concluded that gender practices became more varied in contexts where 
people were drinking, but because of the alcohol 'excuse', gender structures were not challenged: "Bars are thus locations where the boundaries of gender are redrawn, recreated, and reinvented because of the time-out period afforded by alcohol use" (p390-392).

Our study addressed this gap in the literature. We used a qualitative approach to explore how LGBT people experienced and understood alcohol consumption (on the commercial gay scene and elsewhere). We were particularly interested in whether, and how, constructions of identity were important to their drinking practices.

\section{Methods}

We conducted a qualitative study to explore the social context of drinking among LGBT people in Scotland, United Kingdom. Our study was informed by a social constructionist approach which views the world as having multiple systems of knowledge which are created and maintained through all kinds of social interactions and particularly through language (Burr 2003). Given the intrinsically social nature of drinking, we chose to conduct focus groups with LGBT people who knew each other and could draw on shared experiences (Kitzinger 1994). Previous work exploring perceptions of alcohol has used these methods successfully (Emslie et al. 2012, Lyons and Willott 2008).

Inclusion criteria were that participants were 18 years or older (and so could drink legally in the UK), identified as belonging to a sexual minority or transgender group and drank alcohol but did not perceive themselves as having problems with alcohol. We asked respondents if they would be willing to talk about their 'usual everyday experiences with alcohol', to emphasise that we were not interested in focusing on excessive or problematic drinking. Our 
aim was to recruit a diverse sample by sexual and gender identity and by age (given that age is likely to impact on alcohol consumption and participation in the gay scene). However, our control was limited given that we only recruited the initial participant and then asked them to recruit friends, acquaintances or colleagues to attend the group with them. Ethical approval was granted by the Department of Psychology, Social Work \& Allied Health Sciences Research Ethics Committee, Glasgow Caledonian University.

It was time-consuming to recruit respondents to this study; individuals were often interested but were unable to recruit other LGBT friends or colleagues to take part. Strategies included approaching potential respondents in gay pubs, clubs and on the street and giving out flyers about the study; sending email invitations asking people to forward study information to friends and colleagues and to advertise the study on their Facebook pages; advertising the study via posters in workplaces and supermarkets; approaching LGBT and community groups, and advertising the study through community websites (e.g. Gumtree) and social media (Facebook and Twitter). All of these approaches yielded respondents, but the email invitations, LGBT groups and Gumtree were most successful.

Data collection took place between September 2014 and March 2015. Two researchers (JL \& CE) facilitated the groups which lasted between 45 and 95 minutes. After an explanation of the study and assurances about confidentiality, respondents were asked to give written informed consent and permission for discussions to be recorded. Non-alcoholic drinks were provided. The topic guide included questions about drinking on and off the gay scene, the role of alcohol in coming out, stereotypes about LGBT drinking, alcohol marketing on the gay scene, the role of social media in relation to drinking and socialising, and accessing 
alcohol advice and services. Respondents were given $£ 15$ (around \$20 US dollars) gift vouchers to thank them for participating.

Focus groups involve discursive performances where respondents and researchers position themselves in relation to each other, and in relation to the interview context and the topics discussed (Manderson et al. 2006). When carrying out qualitative research with LGBT people, it has been suggested that researchers who share the same sexual orientation will find it easier to build rapport and to access accounts that have greater validity (Almack 2008). In this study, both facilitators identified as female, cisgender, white, Scottish and heterosexual; one was aged in her early thirties when data collection took place while the other was in her forties. We attempted to build rapport through being open, friendly and interested in the respondents' accounts, and through local knowledge of LGBT groups and the commercial gay scene. It is important to state that a researcher who identified as lesbian, gay, bisexual, queer, non-binary or transgender may have elicited different accounts. However, the complexities of the research context should also be acknowledged. First, elements of identity other than sexual orientation are salient; for example, in this study, respondents discussed the impact of ageing, being a parent and being part of musical subcultures. Different facets of identity are not static and disconnected, but interdependent and constantly constructed in the interview context, with specific characteristics sometimes highlighted and sometimes relatively muted (Broom et al. 2009, Richards and Emslie 2000). Secondly, there are disadvantages as well as advantages in having 'insider' status; 'outsiders' may be able to ask more questions and reveal more 'taken for granted' assumptions (Hayfield and Huxley 2015). Finally, identities such as 'gay' or 'transgender' are not homogenous categories (Almack 2008), and researchers and respondents who may identify as such may not necessarily share similar experiences. 
In total, 33 respondents participated in seven focus groups (Table 1). We succeeded in recruiting a diverse sample of respondents in terms of age range (18 to 52 years; around half - 15/33 - aged over 25 years), sexual identity (11 respondents identified as lesbian, 15 as gay, 3 as bisexual, 1 as heterosexual and 3 as 'other', 'queer' or 'pansexual') and gender identity (15 respondents identified as male, 14 as female, and 4 as transgender or 'gender fluid'). Most respondents indicated they were 'out' with everybody or nearly everybody (29/33) and half frequently or sometimes used the gay scene (17/33). Ten respondents lived with partners, ten lived with parents or relatives, nine lived on their own, three lived with flatmates, while one had 'other' living arrangements. Only two respondents (both lesbians) reported having children. Around half (15/33) were educated to degree level and almost all $(31 / 33)$ were from the majority white population.

\section{(table 1 around here)}

Just before the discussions began, respondents completed a drinking grid which enabled us to estimate the number of units consumed in the last week; each unit represents 8 grams of pure alcohol. Most (27 / 33) respondents reported their consumption was consistent with the 'lower risk' weekly drinking benchmark (14 units or less for women, 21 units or less for men; (Department of Health 2007, Royal College of Psychiatrists 2001) commonly used by UK researchers when data were collected (Frisher et al. 2015, Holmes et al. 2014).

Following Braun \& Clarke's (2006) guidelines for thematic analysis, we moved backwards and forwards through the following six steps: data familiarization; generating initial codes; searching for themes, reviewing themes; defining and naming themes; final analysis and write-up. Focus groups were transcribed verbatim and the transcripts were checked for 
accuracy. Names were replaced with pseudonyms. Transcripts and fieldnotes were read repeatedly and discussed by the authors. One researcher (CE) identified initial codes in the data and sorted these into potential themes, facilitated by the software package QSR Nvivo. This process generated four broad themes (i.e. drinking practices; gender/sexuality; health services; marketing and social media) and 20 sub themes (e.g. drinking practices-lifecourse, gender/sexuality-gay scene, gender/sexuality- drinking stereotypes, health services-discussing alcohol). These themes were reviewed through an ongoing dialogue with all the researchers to ensure they were grounded in the original data. Differences in interpretation were resolved through discussion between the three researchers and, on occasion, with members of the project advisory group. Informed by these discussions, CE then reformulated these initial themes into higher order groupings focusing on drinking contexts and drinking identities. Given our social constructionist approach, and our research questions, we paid particular attention to the interactive processes between participants and their 'performative' use of language to construct identity (Burr 2003).

We use the following conventions when presenting qualitative data below: square brackets indicate our explanation of colloquial terms (e.g. hammered [very drunk]) while three dots (...) indicate some words from the transcript have been deliberately omitted. 


\section{Findings}

\section{Drinking contexts: the centrality of alcohol on the commercial gay scene}

There was general consensus about the heavy drinking culture on the commercial gay scene (CGS): 'it's a bit too manically drunk for my liking' (FG1 = focus group 1); 'I can't go out sober' (FG2); 'it's a culture thing to go on the gay scene, get drunk, so maybe people don't realise they have an issue with alcohol' (FG4); 'the only thing to do is get hammered [very drunk] and have a boogie [dance]' (FG6). Respondents discussed the marketing of particular drinks (i.e. alcopops, shots and spirits) within venues, cheap midweek alcohol promotions and the relaunching of old drinks repackaged to the LGBT community (e.g. Smirnoff with cranberry \& lime). Respondents felt they drank more heavily on the gay scene than they did elsewhere because of the expectation that everyone would be drinking heavily, because going out on the CGS was often associated with 'big' nights out and celebrations when people would be more likely to drink heavily, and / or because it was cheaper than straight venues. There was also a recognition of the heavy drinking culture in Scotland generally ('it's a massive drinking culture and it's getting bigger and bigger and bigger' FG3), which influenced people's drinking whatever their gender or sexual identity. However, participants discussed how LGBT people were more likely to use bars and clubs than heterosexual people because they had more limited options to socialise and were less likely to have parental responsibilities which might limit drinking. They also suggested that marginalised groups (particularly bisexual and transgender people) might drink more because of isolation and double discrimination (from both outside and within the LGBT community).

Participants in every focus group discussed how their drinking had changed over time. The expected trajectory was that people would drink heavily ('going out and getting steaming'; 'getting mad with it') when they first 'came out' and encountered the CGS but that their 
drinking, and use of the scene, would gradually reduce over time. To some extent, this entry into the alcohol-fuelled CGS was perceived as a necessary rite of passage, a way to gain acceptance and, by some, as an important part of LGBT identity. Some discussed the necessity of drinking to give them the confidence to go out and feel accepted on the gay scene ('I've yet to meet another man in sobriety. I'm always drunk, it's my confidence' FG3; see also Peralta, 2008), a space where LGBT people can express their identities and have these identities validated by others (Valentine and Skelton 2003).

However the idea that people simply 'grew out' of the scene (and excessive drinking) as they got older and acquired more responsibilities was challenged by respondents' accounts. First, respondents in midlife described continuing strong peer pressure to drink. Those who chose not to drink on some occasions discussed how this 'alarmed' people, ended conversations (sometimes with previously interested admirers) and could lead to hostility. Similar findings have been reported from respondents in the west of Scotland who did not identity as LGBT (Emslie et al, 2012). Secondly, some respondents described how their drinking had stayed at the same level, or increased, since 'coming out', often due to increased income. Thirdly, respondents generally associated the break-up of relationships with spending more time on the CGS and more drinking. These life events could happen at any age and disrupted the general assumption of reduced drinking as one aged. Finally, the assumption that increased responsibilities led to decreased drinking was rarely mentioned by respondents, although some discussed this in relation to work commitments. Only two respondents in the study had children. They described how this limited their drinking and were scornful of the notion of spontaneous midweek nights out described by others in their group ('We have children. You don't go out on a Wednesday when you have children!': FG6). Respondents in two groups (FG2 and FG7) described how their dogs limited their drinking to some extent ('It might 
sound quite gay but I've got a dog so I can't go out and get pissed [drunk] and then fester in my bed the next day' (FG2); 'We go to dog-friendly bars so that kind of puts paid to ... any kind of sliding ... staying for five hours (in the pub)' (FG7). However, these responsibilities did not apply to most respondents in the sample.

\section{Drinking identities}

It was clear from our data that drinking alcohol - particularly the choice of drink and drinking vessel - was an important part of identity construction for these LGBT respondents.

Respondents discussed stereotypical expectations of what gay men and lesbians drink (alcopops, spirits or sweet colourful cocktails; and pints of beer, real ale or Guinness respectively) and commented on how this was a reversal of the stereotypes usually associated with straight men and women's drinking:-

$F G 2$

Greg: You'd never get my (straight) brother having a candy floss Martini and I had one last week, so ... something like that. ... My brother's more ... pints of beer and cider and things like that, whereas I very rarely have that.

Alison: I think lesbians drink the same as guys (agreement) ... Like, lesbians will happily just go and sit with a pint. ... I don't think a straight lassie [girl] would do that.

Claire: I think it's a role reversal. Like, if you went to a straight place the guys would have pints and the girls would have ... vodkas but then if you're on the gay scene then it's the other way about (agreement).

When asked to state their favourite drink at the beginning of the group discussions, only half of the gay men (7/15) chose spirits or cocktails and around one quarter (3/11) of the lesbians selected beer or Guinness. Given these preferences, some groups dismissed stereotypes, stating that LGBT people drank a range of different drinks and observed that straight women, as well as gay women, drank pints because this was now socially acceptable. Others were 
aware of the stereotypes but were clear that they tended to drink what was cheap or on promotion. With the exception of one teenage gay man, all of those who discussed the cost of drinking identified as female or transgender.

However, even when stereotypes were dismissed as inaccurate, they were still thought to pressure people to drink 'appropriately' in order to 'fit in'. Respondents gave a range of examples of people being surprised when the choice of drink and perceived sexual identity of the drinker did not 'match' as expected:-

FG1

Chris: The obvious kind of stereotype is that straight men drink beer ... and that gay men ... drink cocktails ... By and large, I think it's more or less accurate ... But I think there is a certain pressure to drink what you're expected to drink. I've got a male straight friend who doesn't like beer ... he asks for like a vodka lemonade ... he gets teased about it and it's a joke. I mean, it's nothing serious but I always find that quite ridiculous just cause I think why does it matter? ... I think in these kind of things obviously there is a stereotype there for that joke to be made.

Simon: I think there's ... a stereotype and it works both ways. I've been in gay bars and had a pint of real ale or something and people have looked at me and "What's that you're drinking?"

FG6

Pippa: There's definitely stereotypes cause I don't know how many times ... when I've been in mainstream, straight venues and I will drink pints and then you get folk going, "What are you drinking a pint for? Are you a lesbian?" "I just like pints."... It's nothing to do with my sexuality".

Paul: With gay men, if you drink a pint that means you're straight ... They kinda, like they get shocked when you drink a pint, they're like, "Oh, I've never seen that. I thought you were on like poof juice or whatever."

Pippa: Yeah, the very term "poof juice”!

Paul's use of the disparaging term 'poof juice', above, also illustrated the clear connection between alcohol and identity construction. This term was applied to sweet pre-mixed spirits served in individual bottles ('alcopops', 'coolers', 'RTD - ready to drink') with a relatively 
low alcohol content (usually around 5\% to 7\% ABV [alcohol by volume]) such as WKD, Bacardi Breezers, Smirnoff Ice and Hooch. Lesbians in FG2 used the term themselves when discussing drinking alcopops at home:-

FG2

Caroline: Personally, for me, I don't like to get pissed [drunk] in the house so if I'm gonna be drinking it'll be something that I really like, like Malibu or, like, poof juice. (laughter)

Can I ask what...? Poof juice has come up before. Why would it be called poof juice?

Jacqui: Cause it doesn't get you drunk.

Alison: It's got nothing in it.

Caroline: You'd need to drink a million of them to feel anything.

Some discussions linked appearance (hair and clothing), as well as drinking, to identity construction. For example, Jacqui in FG2 suggested that 'you automatically think of a lesbian with short hair, a checked shirt, a pint'. The combination of these different signifiers was important. For example, Pippa described how she deliberately chose her drink in order to display her sexual identity in certain contexts. Her extract demonstrated her awareness that having long hair and drinking WKD on the scene might signify 'straight chick', but that choosing to drink a pint would signify 'dyke':-

FG6

Pippa: If I wasn't in a relationship and did have any intention of going out on the pull [looking for a sexual partner] on the scene, I would drink pints, simply because no one looks at me and immediately recognises ... "Well, she looks like a dyke"... I'm the imposter on the gay scene - everyone just looks at me and makes the automatic assumption that I'm straight 'cause I've got long hair... but drinking pints is that sort of, it's like my ticket to ride. "Look ladies, I've got a pint, I'm one of you!' Whereas if I was sitting with a blue WKD, I'm pretty sure everyone would just be like "Straight chick in the corner, we'll just ignore her."... I mean I do enjoy pints anyway. I drink pints quite often, but...

Eva: It wouldn't just be because you fancied a pint? 
Pippa: No, it would be because I fancied the chicks ... (laughs). Want them to notice that I'm not the straight chick in the pub!

This awareness of how appearance and drinks were interpreted by others was also demonstrated by lesbians in FG2. When 'going straight' (i.e. to straight pubs and clubs), these women discussed dressing up and wearing heels to fit in with their straight female friends and in order to get into some smarter straight venues. Those women who usually drank cider or spirits said they would continue doing so but Jacqui discussed changing her drink from a pint to spirits; her account suggested she would feel incongruous dressed like a straight woman while drinking pints (like a lesbian):-

$F G 2$

Jacqui: All my pals from school are straight ... I don't drink as much when I go out with them ... because I'm not gonna sit with a pint and dress and heels and stuff so ... I'm sitting with a vodka.

Caroline: Yeah. Like, see for me personally, I'll go straight only once in a blue moon but when I do it's like I don't feel that comfortable even though I've got the dress and the shoes and all that on, I'll drink but it's more expensive as well ... I wouldn't feel comfortable going out ... in a nice pair of jeans and a top if they're all wearing dresses and heels and stuff.

Some transgender respondents were particularly aware of their choice of drink as a prop to express their identity and to challenge people's preconceptions. For example, Stella described her reaction to being criticised for drinking out of a pint glass rather than a (feminised) half pint glass:-

FG3

Stella: I did get criticised for not drinking a half pint ... Somebody actually walked up to me: "What are you doing with a full pint? Women should drink half pints ... And I went, "I don't give a shit. I used to be a man!" 
Naomi was particularly explicit about her choice of drink, along with her appearance (drag, beard, monobrow) being part of her gender performance which was deliberately subversive ('gender fucking'):-

FG6

Naomi: It just kinda comes down to this whole masculinity and femininity thing ... cause like lesbians ... they're all butch, and the gay men ... they're all sissies and so like they will drink the sweet and colourful ... and the lesbians will only drink the pints of Guinness ... I don't identify as male or female either ... (so) people get like, "Oh what are you drinking?" And then sometimes people get really confused about that because they don't know which kind of, which cliché to put on me ... If I'm all in drag I like to drink like the manliest drink that I can find just to piss people off ... My drag is kind of subversive, and really obviously gender fucking ... like with beard ... and a monobrow ... I tend to then on purpose kind of play around with these stereotypes ... I'll make a point of drinking a pint because it's like, part of my performance.

However, respondents were clear that sexual and gender identity were only part of the picture when considering alcohol consumption. As previously discussed, position in the (LGBT) lifecourse was also important; sexual identity might be relevant to drinking when first out on the commercial gay scene but older respondents suggested this changed as they aged. In addition, other identities ('student', 'metal fan') could be more salient for drinking than 'gay' or 'lesbian'. In the extract below, Charlie suggested that while being LGB or T might be one 'trigger amongst a wide range of triggers' for heavy drinking, other factors were important too. The extract from respondents in FG6 also illustrated this point as they explained how their identification with particular music scenes had much more influence on their drinking than gender or sexual identity:-

FG1

Charlie: Being L, G, B or T could be a trigger amongst a wider range of triggers (for heavy drinking.) (Like) people who are starting further education ... it's part of the kind of hedonistic student lifestyle, or it can be. But I think there's also that thing if you're newly out, whether you're young or old or whatever your age, if you're newly out, there's that potential that you might actually be accessing the commercial gay scene for the first time and get caught up or sucked into that culture of over-indulging in alcohol. 


\section{FG6}

Naomi: Sexual orientation ... related to my alcohol use? I'd be like, "No"... and like with my gender identity as well ... it doesn't relate ... The people that I socialise with ... some of them just tend to be LGBT. The others tend to be a lot like the whole metal and goth stuff ... that's just a big part of my socialisation but we tend to drink and so it's like

Eva: Yeah, I don't think my sexuality would have anything to do with it to be honest. I mean I come from the metal scene as well when I was 18, and we done a hell of a lot more drinking than I do now. A hell of a lot more. (agreement) When I went out to rock clubs we done a lot more drinking than, I don't think I could even handle that anymore at all. I think I'd end up in hospital.

It is therefore important to acknowledge the diversity of identity 'frames' that respondents referred to in their accounts, illustrating the interaction between gender and sexual identity and other markers of identity in performances of self.

\section{Discussion}

Our study found that alcohol played a key role in identity construction for LGBT people in Scotland. Respondents described the necessity of consuming alcohol to gain courage to first access the gay scene, the expectation that heavy drinking would continue to form an integral part of 'nights out' on the gay scene, and persistent peer pressure to drink across the lifecourse. The conventional binary opposition (pints of beer signify 'masculinity', sweet colorful cocktails and alcopops signify 'femininity') was reversed to signify nonheteronormativity (i.e. lesbians drink pinks of beer while gay men drink cocktails and alcopops). Even when respondents rejected these stereotypes, there was a sense that these powerful associations still influenced people's drinking practices. The use of derogatory terms such as 'poof juice' to refer to alcopops illustrates clear associations between drinking and gender and sexual identity (Galloway et al. 2007), and demonstrates how homophobic 
insults are used to police men's behaviour (Plummer 1999). Previous research has found that men who do not 'do' gender appropriately when drinking (i.e. consume pints of beer) risk being labelled 'gay' (de Visser \& Smith, 2007; Emslie et al, 2013), 'ponces' (Emslie et al, 2013; Willott \& Lyons, 2012), 'poofs' (de Visser \& Smith, 2007) or 'two beer queers' (Peralta 2007). However, our study illustrates that gay men are also subject to scrutiny and sanction for not drinking 'appropriately'. As Peralta \& Jauk (2011) argue "asking questions about who uses alcohol, when, how much, and why reveals processes of gender construction and marginalization" (p882).

Research with respondents who identify as heterosexual has also found that quantity of alcohol consumed, choice of drink, and drinking vessel demonstrate 'who you are' to (potential) friends and partners (de Visser and McDonnell 2012, MacLean 2016, Niland et al. 2014). However, our study suggests that drinking as a social practice through which people demonstrate a sense of self may be more deliberate and pronounced among LGBT respondents, given their contested subjectivities. For example, lesbians' awareness of how appearance and drinking combine to display particular gender identities is similar to earlier work illustrating how women in early midlife matched different drinks and clothes to different gendered identities at different times (e.g. matching a dress and heels with wine or cocktails 'just to be girly' compared to trainers and jeans and a pint of beer or real ale when 'playing the lad', (Emslie et al. 2015). However, the additional identity work required from lesbian and bisexual women in considering what to wear and drink when 'passing' as straight (e.g. wearing a dress and heels and drinking vodka) or when signalling their sexual identity (drinking a pint on the scene rather than an alcopop to signify being a 'dyke ... on the pull' and not a 'straight chick') is notable. In addition, recent research has highlighted the complexity and diversity of lesbian (e.g. 'butch' and 'femme') as well as gay (e.g. 'gay lad', 
'twink', 'bear') identities (Peralta and Jauk 2011, Ravenhill and de Visser in press) Future research should focus on how these diverse sub-groups deploy alcohol in order to align themselves with different identities.

Our paper makes an original and significant contribution to the literature. The meaning of alcohol consumption for sexual minority groups is rarely studied and, to our knowledge, this is the first study to include transgender and gender fluid respondents. Our findings have implications for health practitioners; understanding the central role of identity in drinking practices is vital when trying to build interventions to reduce harm among particular populations and eliminate barriers for help seeking if people are concerned about their drinking. Our findings are also significant as they demonstrate the importance of gaining a broad sample of LGBT respondents, rather than only focusing on younger people's experiences on the commercial gay scene. LGBT people drink at home, at gigs, on the 'alternative' gay scene, in mainstream (heterosexual) venues and on the gay scene with straight friends. Identity is complex; at some points in the lifecourse, identifying as LGBT may be linked to drinking behaviours, but at other points different social roles or identities ('parent', 'music fan', 'student') may be more salient. A study which focused on a narrow section of the LGBT community may have misattributed all drinking practices to respondents' sexual or gender identity. Finally, our research adds to theoretical debates around gender. It has been suggested that the structural contexts in which gay and lesbian people live may lead to the disassembling of 'taken-for-granted' gendered norms (Reczek and Umberson 2012). However, our data suggest that sexual minority - as well as heterosexual respondents are 'called to account' for failing to 'do' gender appropriately (West and Zimmerman 1987) (e.g. consuming the 'wrong' drink for a gay man). In contrast, transgender /non-binary respondents explicitly discussed their 'performance' of gender and 
reflected on how their non-traditional gender identity allowed, and even encouraged, transgressions and reconstructions of identity. Their well-considered use of alcohol (and dress) to demonstrate sexual and gender identity in our study is notable and may usefully feed into wider debates about gender performance, construction of masculinities and femininities, and drinking.

Like all studies, ours had limitations. First, although we tried to reach a broad range of LGBT people, with the exception of the teenagers in focus group 3, we did not recruit respondents who never accessed the commercial gay scene. We are also aware that we would have benefitted from a bigger sample of transgender respondents, given that this heterogeneous group includes trans-men, trans-women and transgender non-binary people. Secondly, we chose to use discussion groups comprised of friends and colleagues because we wanted to explore shared accounts of drinking and socialising. However, it is possible that the group context may have made it more difficult for some respondents to disagree with the majority view (although there were certainly differences of opinion expressed within the groups). It is also important to remember that respondents were not just describing their drinking within the interview context, they were also 'performing' identity within the focus group discussions.

At a broader level, the alcohol industry is well aware that drinking alcohol is an important part of identity construction and has skilfully linked their products to friendship, sociability and attractiveness (for both men and women) and, following the tobacco industry, pleasure, time out and independence for women (Hastings 2010). Many brands have positioned themselves as 'gay friendly'. For example, Bud Light and brewer SABMiller have sponsored Gay Pride in different UK and US cities, while Smirnoff and Absolute vodka have run social 
media campaigns supporting gay marriage. Further work should focus on the targeted marketing of alcohol to LGBT communities through alcohol promotion on the commercial gay scene, and through social and traditional media.

\section{Acknowledgements}

We would like to acknowledge our excellent steering group who offered very useful advice around recruitment, literature and interpretation of data and devoted a considerable amount of time to meetings and email exchanges (Nicola Boydell, Nicky Coia, Barbara Duncan, Niamh Fitzgerald and Jamie Frankis). We would also like to thank Eric Carlin for his considerable support and helpful suggestions, Susan Kerr and Alasdair Forsyth for excellent comments on the paper and Louise Carroll, Lisa McDaid, Andy McAuley and Suzanne Grant for suggestions about recruitment. A short version of this paper was presented at the Kettil Bruun Society's annual symposium in June 2016; many thanks to Sarah MacLean for her extremely helpful feedback as discussant which helped greatly when rewriting the discussion section. Most of all, we would like to thank our participants for talking so freely about their lives and their drinking This work was funded by Scottish Health Action on Alcohol Problems (SHAAP). 


\section{References}

Allen, J.L. and Mowbray, O. (2016) Sexual orientation, treatment utilization, and barriers for alcohol related problems: Findings from a nationally representative sample, Drug and Alcohol Dependence, 161, 323-330.

Almack, K. (2008) Women parenting together: a reflexive account of the ways in which the researcher's identity and experiences may impact on the processes of doing research, Sociological Research Online, 13, 1, 4 http://www.socresonline.org.uk/13/1/4.html.

Bloomfield, K., Wicki, M., Wilsnack, S., Hughes, T. and Gmel, G. (2011) International Differences in Alcohol Use According to Sexual Orientation, Substance Abuse, 32, 4, 210-219.

Bobrova, N., West, R., Malyutina, D., Malyutina, S. and Bobak, M. (2010) Gender Differences in Drinking Practices in Middle Aged and Older Russians, Alcohol and Alcoholism, 45, 6, 573-580.

Braun, V. and Clarke, V. (2006) Using thematic analysis in psychology, Qualitative Research in Psychology, 3, 2, 77-101.

Broom, A., Hand, K. and Tovey, P. (2009) The role of gender, environment and Individual biography in shaping qualitative interview data, International Journal of Social Research Methodology, 12, 1, 51-65.

Buffin, J., Roy, A., Williams, H. and Winter, A. (2011) Part of the Picture: Lesbian, gay and bisexual people's alcohol and drug use in England (2009-2011). Lesbian and Gay Foundation, University of Central Lancashire: Lesbian and Gay Foundation.

Burr, V. (2003) Social constructionism, London, England: Routledge.

Cáceres, C.F. and Cortiñas, J.I. (1996) Fantasy Island: An Ethnography of Alcohol and Gender Roles in a Latino Gay Bar, Journal of Drug Issues, 26, 1, 245-260.

Campbell, H. (2000) The Glass Phallus: Pub(lic) Masculinity and Drinking in Rural New Zealand, Rural Sociology, 65, 4, 562-581.

de Visser, R.O. and McDonnell, E. (2012) 'That's OK. He's a guy': A mixed-methods study of gender double-standards for alcohol use, Psychology \& Health, 27, 5, 618-639.

de Visser, R.O. and Smith, J.A. (2007) Alcohol consumption and masculine identity among young men, Psychology and health, 22, 5, 595-614.

de Visser, R.O., Wheeler, Z., Abraham, C. and Smith, J.A. (2013) 'Drinking is our modern way of bonding': young people's beliefs about interventions to encourage moderate drinking, Psychology \& Health, 1-21.

Department of Health (2007) Safe. Sensible. Social. The next steps in the National Alcohol Strategy. , London: Home office.

Drabble, L. (2000) Alcohol, tobacco, and pharmaceutical industry funding: Considerations for organizations serving lesbian, gay, bisexual, and transgender communities., Journal of Gay \& Lesbian Social Services, 11, 1, 1-26.

Dumbili, E.W. (2015) 'What a man can do, a woman can do better': gendered alcohol consumption and (de)construction of social identity among young Nigerians, $B M C$ Public Health, 15, 1, 1-12.

Emslie, Hunt, K. and Lyons, A. (2012) Older and wiser? Men's and women's accounts of drinking in early mid-life, Sociology of Health \& Illness, 34, 4, 481-496.

Emslie, Hunt, K. and Lyons, A. (2013) The role of alcohol in forging and maintaining friendships amongst Scottish men in mid-life Health Psychology special issue on men's health, 32, 1, 33-41.

Emslie, C., Hunt, K. and Lyons, A. (2015) Transformation and time-out: The role of alcohol in identity construction among Scottish women in early midlife, International Journal of Drug Policy, 26, 5, 437-445. 
Frisher, M., Mendonça, M., Shelton, N., Pikhart, H., de Oliveira, C. and Holdsworth, C. (2015) Is alcohol consumption in older adults associated with poor self-rated health? Cross-sectional and longitudinal analyses from the English Longitudinal Study of Ageing, BMC Public Health, 15, 1, 703.

Galloway, J., Forsyth, A. and Shewan, D. (2007) Young People's Street Drinking Behaviour: Investigating the Influence of Marketing \& Subculture Alcohol Insight 44, London: Alcohol Education and Research Council

Gonzales, G., Przedworski, J. and Henning-Smith, C. (2016) Comparison of health and health risk factors between lesbian, gay, and bisexual adults and heterosexual adults in the united states: Results from the national health interview survey, JAMA Internal Medicine, 176, 9, 1344-1351.

Gough, B. and Edwards, G. (1998) The beer talking: four lads, a carry out and the reproduction of masculinities, The Sociological Review, 46, 3, 409-455.

Griffin, C., Szmigin, I., Bengry-Howell, A., Hackley, C. and Mistral, W. (2013) Inhabiting the contradictions: Hypersexual femininity and the culture of intoxication among young women in the UK, Feminism \& Psychology, 23, 2, 184-206.

Guasp, A. (2011) Gay and Bisexual Men's Health Survey: Stonewall.

Harnett, R., Thom, B., Herring, R. and Kelly, M. (2000) Alcohol in transition: Toward a model of young men's drinking styles, Journal of Youth Studies, 3, 1, 61-77.

Hastings, G. (2010) "They'll drink bucket loads of the stuff". An analysis of internal alcohol industry advertising documents, Stirling: Institute for Social Marketing, University of Stirling and the Open University.

Hayfield, N. and Huxley, C. (2015) Insider and Outsider Perspectives: Reflections on Researcher Identities in Research with Lesbian and Bisexual Women, Qualitative Research in Psychology, 12, 2, 91-106.

Ho, S.-L. (2015) 'License to drink': White-collar female workers and Japan's urban night space, Ethnography, 16, 1, 25-50.

Holmes, J., Meng, Y., Meier, P.S., Brennan, A., Angus, C., Campbell-Burton, A., Guo, Y., Hill-McManus, D. and Purshouse, R.C. (2014) Effects of minimum unit pricing for alcohol on different income and socioeconomic groups: a modelling study, The Lancet, 383, 9929, 1655-1664.

Holt, M. and Griffin, C. (2003) Being Gay, Being Straight and Being Yourself: Local and Global Reflections on Identity, Authenticity and the Lesbian and Gay Scene, European Journal of Cultural Studies, 6, 3, 404-425.

Hughes, T. and Eliason, M. (2002) Substance Use and Abuse in Lesbian, Gay, Bisexual and Transgender Populations, Journal of Primary Prevention, 22, 3, 263-298.

Hunt, R. and Fish, J. (2008) Prescription for change: Lesbian and bisexual women's health check De Montfort University: Stonewall.

Keogh, P., Reid, D., Bourne, A., Weatherburn, P., Hickson, F., Jessup, K. and Hammond, G. (2009) Wasted opportunities. Problematic alcohol and drug use among gay men and bisexual men., London: Sigma Research.

King, M., Semlyen, J., Tai, S.S., Killaspy, H., Osborn, D., Popelyuk, D. and Nazareth, I. (2008) A systematic review of mental disorder, suicide, and deliberate self harm in lesbian, gay and bisexual people. BMC psychiatry, 8(1), 70., BMC Psychiatry, 8, 1, 70.

Kitzinger, J. (1994) The methodology of focus groups: the importance of interaction between research participants, Sociology of Health \& Illness, 16, 1, 103-121.

Lemle, R. and Mishkind, M.E. (1989) Alcohol and masculinity, Journal of Substance Abuse Treatment, 6, 4, 213-222. 
Lyons, A.C. and Willott, S.A. (2008) Alcohol consumption, gender identities and women's changing social positions, Sex Roles, 59, 9-10, 694-712.

MacLean, S. (2016) Alcohol and the Constitution of Friendship for Young Adults, Sociology, $50,1,93-108$.

Manderson, L., Bennett, E. and Andajani-Sutjahjo, S. (2006) The Social Dynamics of the Interview: Age, Class, and Gender, Qualitative Health Research, 16, 10, 1317-1334.

Meads, C., Pennant, M., McManus, J. and Bayliss, S. (2009) A systematic review of lesbian, gay, bisexual and transgender health in the West Midlands region of the UK compared to published UK research, Birmingham: University of Birmingham. DPHE report number 71 .

Moncrieff, M. (2014) Out of your mind. Improving provision of drug and alcohol treatment for lesbian, gay, bisexual \& trans people, London: London Friend.

Mullen, K., Watson, J., Swift, J. and Black, D. (2007) Young men, masculinity and alcohol, Drugs: Educucation Prevention \& Policy, 14.

Niland, P., Lyons, A.C., Goodwin, I. and Hutton, F. (2014) ‘See it doesn’t look pretty does it?'Young adults' airbrushed drinking practices on Facebook. Psychology \& health, 29(8), 877-895., Psychology \& Health, 29, 8, 877-895.

Office for National Statistics (2013) Chapter 2 - Drinking (General Lifestyle Survey Overview - a report on the 2011 General Lifestyle Survey), http://www.ons.gov.uk/ons/dcp171776 302636.pdf (Accessed 3 July 2015).

Peralta, R.L. (2007) College alcohol use and the embodiment of hegemonic masculinity among European American men, Sex Roles, 56, 11/12, 741-756.

Peralta, R.L. (2008) "Alcohol allows you to not be yourself". Towards a structured understanding of alcohol use and gender difference among gay, lesbian, and heterosexual youth Journal of Drug Issues, 38, 2, 373-399.

Peralta, R.L. and Jauk, D. (2011) A Brief Feminist Review and Critique of the Sociology of Alcohol-Use and Substance-Abuse Treatment Approaches, Sociology Compass, 5, 10, 882-897.

Ravenhill, J.P. and de Visser, R.O. (2016) "There are too many gay categories now". Discursive constructions of gay masculinity, Psychology of Men \& Masculinity. Advance online publication. doi:10.1037/men0000057

Reczek, C. and Umberson, D. (2012) Gender, health behavior, and intimate relationships: Lesbian, gay, and straight contexts, Social Science \& Medicine, 74, 11, 1783-1790.

Richards, H. and Emslie, C. (2000) The 'doctor' or the 'girl from the University'? Considering the influence of professional roles on qualitative interviewing, Family Practice, 17, 1, 71-75.

Royal College of Psychiatrists (2001) Alcohol - can the NHS afford it?, London: Royal College of Physicians.

Simonen, J., Törrönen, J. and Tigerstedt, C. (2014) Femininities of drinking among Finnish and Swedish women of different ages, Addiction Research \& Theory, 22, 2, 98-108.

Stead, M., MacAskill, S., MacKintosh, A.-M., Reece, J. and Eadie, D. (2001) "It's as if you're locked in": qualitative explanations for area effects on smoking in disadvantaged communities, Health \& Place, 7, 4, 333-343.

Thurnell-Read, T. (2011) Off the Leash and Out of Control: Masculinities and Embodiment in Eastern European Stag Tourism, Sociology, 45, 6, 977-991.

Valentine, G. and Skelton, T. (2003) Finding oneself, losing oneself: the lesbian and gay 'scene' as a paradoxical space, International Journal of Urban and Regional Research, $27,4,849-866$. 
Varney, J. (2008) A review of drugs and alcohol use amongst the lesbian, gay, bisexual and transgender community in London, London: Metropolitan Police lesbian, gay, bisexual and transgender independent advisory.

West, C. and Zimmerman, D.H. (1987) Doing gender, Gender and Society, 1, 2, 125-151.

Willott, S. and Lyons, A.C. (2012) Consuming Male Identities: Masculinities, Gender Relations and Alcohol Consumption in Aotearoa New Zealand, Journal of Community \& Applied Social Psychology, 22, 4, 330-345.

Wolff, B., Busza, J., Bufumbo, L. and Whitworth, J. (2006) Women who fall by the roadside: gender, sexual risk and alcohol in rural Uganda, Addiction, 101, 9, 1277-1284.

Yuan, N.P., Eaves, E.R., Koss, M.P., Polacca, M., Bletzer, K. and Goldman, D. (2010) "Alcohol is Something That Been With Us Like a Common Cold": Community Perceptions of American Indian Drinking, Substance Use \& Misuse, 45, 12, 19091929. 
Table 1 Description of discussion groups and respondents

\begin{tabular}{|c|c|c|c|c|c|}
\hline Group (age range) & LGB or T? & 'Out' with? & Use gay scene? & Alcohol in last week & N. 'hazardous' \& 'harmful'1 \\
\hline 1. Gay men's sports group (25-51 yrs) & 4 gay men & $\begin{array}{l}\text { Everybody (3) / } \\
\text { Nearly everybody } \\
\text { (1) / }\end{array}$ & $\begin{array}{l}\text { Rarely (3) / } \\
\text { Sometimes (1) }\end{array}$ & 2-27 units & 1 'hazardous' \\
\hline 2. Bar group (20-25 yrs) & 5 lesbians \& 1 gay man & $\begin{array}{l}\text { Everybody (5) / } \\
\text { Nearly everybody } \\
(1) /\end{array}$ & $\begin{array}{l}\text { Frequently (4)/ } \\
\text { Rarely (1), no } \\
\text { answer (1) }\end{array}$ & 4-76 units & $\begin{array}{l}1 \text { 'hazardous' } \\
1 \text { 'harmful' }\end{array}$ \\
\hline 3.HIV charity workers (32-52 yrs) & $\begin{array}{l}1 \text { lesbian, } 3 \text { gay men, } 1 \\
\text { bisexual man, } 1 \\
\text { transgender respondent }\end{array}$ & $\begin{array}{l}\text { Everybody (5), } \\
\text { Most (1) }\end{array}$ & $\begin{array}{l}\text { Frequently (2), } \\
\text { Sometimes (1), } \\
\text { Rarely (3) }\end{array}$ & 2-73 units & 1 'harmful' \\
\hline 4. LGBT support workers (27-41 yrs) & $\begin{array}{l}3 \text { lesbians, } 1 \text { bisexual } \\
\text { woman, } 1 \text { transgender } \\
\text { respondent }\end{array}$ & $\begin{array}{l}\text { Everybody (4), } \\
\text { Some (1) }\end{array}$ & $\begin{array}{l}\text { Rarely (3), } \\
\text { Sometimes (2) }\end{array}$ & $0-7$ units & 0 \\
\hline 5. LGBT community group (18-24 yrs) & $\begin{array}{l}1 \text { lesbian, } 3 \text { gay men, } 1 \\
\text { transgender respondent }\end{array}$ & $\begin{array}{l}\text { Everybody (3), } \\
\text { Nearly everybody } \\
(1), \text { Most (1) }\end{array}$ & $\begin{array}{l}\text { Never (3), } \\
\text { Sometimes (1), } \\
\text { Frequently (1) }\end{array}$ & $0-2$ units & 0 \\
\hline 6. LGBT youth workers (19-34 yrs) & $\begin{array}{l}1 \text { gay man, } 2 \text { bisexual / } \\
\text { pansexual women, } 1 \\
\text { transgender respondent }\end{array}$ & $\begin{array}{l}\text { Everybody (3), } \\
\text { Few (1) }\end{array}$ & $\begin{array}{l}\text { Frequently (2), } \\
\text { Sometimes (2) }\end{array}$ & $0-35$ units & 1 'hazardous' \\
\hline 7. Lecturers (41-46 yrs) & 2 gay men \& 1 lesbian & Everybody (3) & $\begin{array}{l}\text { Rarely (2) / } \\
\text { Sometimes (1) }\end{array}$ & $6-25$ units & 1 'hazardous' \\
\hline
\end{tabular}

1 'Hazardous' drinking: 22-50 units for men in a week, 15-35 units for women in a week. 'Harmful' drinking:>50 units for men in a week, >35 units for women in a week (Department of Health 2007, Royal College of Psychiatrists 2001) 
